\title{
Continuous Glucose Monitoring Effects on Blood Glucose Management in Diabetic Patients on Hemodialysis-Results in the Patients from Single Hospital
}

\author{
Moritsugu Kimura, Masao Toyoda*, Nobumichi Saito, Yosuke Nakagawa and Masafumi Fukagawa \\ Division of Nephrology and Metabolism, Department of Internal Medicine, Tokai University School of Medicine, Kanagawa, Japan
}

*Corresponding author: Masao Toyoda, Division of Nephrology and Metabolism, Department of Internal Medicine, Tokai University School of Medicine, Kanagawa, Japan, Tel: +81-463-93-1121-2490; Fax: +81-463-91-3350; E-mail: m-toyoda@is.icc.u-tokai.ac.jp

Received date: October 19, 2017; Accepted date: October 27, 2017; Published date: October 30, 2017

Copyright: () 2017 Kimura M, et al. This is an open-access article distributed under the terms of the Creative Commons Attribution License, which permits unrestricted use, distribution, and reproduction in any medium, provided the original author and source are credited.

\begin{abstract}
Objective: Diabetic patients on hemodialysis $(\mathrm{HD})$ are prone to develop treatment-related serious hypoglycemia due to poor renal clearance of insulin and augmented drug efficacy, often resulting in withdrawal of insulin. Consequently, many patients are erroneously switched to oral glucose-lowering agents or diet therapy alone, without self-monitoring of blood glucose (SMBG). Therefore, we hypothesized that continuous glucose monitoring (CGM) may be useful for optimizing glycemic control and clinical management in diabetic patients on HD.
\end{abstract}

Methods: In this study, 8 type 2 diabetic patients on HD who did not use SMBG after withdrawal of insulin and start of oral glucose-lowering agents, were recruited to measure and evaluate blood glucose with CGM. These patients thought to be controlled within glycemic control target proposed by the Japanese Society for Dialysis Therapy. Predialysis casual plasma glucose level (or 2-h postprandial plasma glucose level) of $<180-200 \mathrm{mg} / \mathrm{dL}$ and GA level $<20.0 \%$

Results: Although the levels of glycated albumin (GA) and blood glucose measured just before HD were within the provisional target values recommended by the Japanese Society for Dialysis Therapy in all eight patients, seven patients developed postprandial hyperglycemia (>200 mg/dl) after HD.

Conclusions: Diabetic patients on HD require careful monitoring with SMBG, CGM, and direct measurement of postprandial blood glucose level during HD before any decision is made regarding withdrawal of insulin and cessation of SMBG.

Keywords: Type 2 diabetes; Hemodialysis; CGM; Insulin therapy; SMBG; Questionnaire survey; Glycated albumin

\section{Introduction}

Diabetic patients on hemodialysis (HD) are prone to develop complications related to micro- and macro-angiopathies. Therefore, careful blood glucose management of such patients is important. In Japan, medical examinations of diabetic patients on HD are almost carried out by the dialysis physician instead of diabetes specialists, and the dialysis physicians are expected to acquire skills of blood glucose management. For this reason, The Japanese Society for Dialysis Therapy published guide in 2012 [1]. It recommends the following tentative targets for glycemic control: predialysis casual plasma glucose level (or 2-h postprandial plasma glucose level) of $<180-200 \mathrm{mg} / \mathrm{dL}$. The tentative target for glycemic control in HD patients is GA level $<20.0 \%$. Furthermore, target GA levels of $<24.0 \%$ are suggested for HD patients with history of cardiovascular events and hypoglycemia. However, there are many cases that can't continue fine blood glucose management. Because they are erroneously switched to oral glucoselowering agents or diet therapy alone, without insulin, self-monitoring of blood glucose (SMBG) for reasons such as patients with diabetic nephropathy becoming prone to develop treatment-related serious hypoglycemia due to poor renal clearance of insulin and augmented drug efficacy [2]. Continuous glucose monitoring (CGM) can detect asymptomatic hypoglycemia or hyperglycemia and is often used for the clinical management and assessment of glycemic control $[3,4]$. We hypothesized that CGM may be useful for optimizing glycemic control and clinical management in diabetic patients on HD. In this study, diabetic patients on HD who did not use SMBG after withdrawal of insulin were recruited for measurement and evaluation of blood glucose with CGM.

\section{Patients and Methods}

\section{Patients and treatment protocol}

The following criteria were used for inclusion in the study: 1) insulin treatment in the past followed by withdrawal, 2) currently on maintenance HD, 3) no use of SMBG after insulin withdrawal, and 4) consent for CGM monitoring during the 12-month study period. Although the precise reason was unknown, insulin was discontinued in all patients upon judgments of fellows of the dialysis therapy. CGM was performed on both the HD day and non-HD day using a professional CGM iPro2 (Medtronic, Minneapolis, MN). Following records for 7 days of CGM, the treatment was adjusted based on the obtained CGM data. After introduction dialysis, in 6 patients, insulin was switched to $50 \mathrm{mg} /$ day vildagliptin, and $6.25-12.5 \mathrm{mg} /$ day 
Citation: Kimura M, Toyoda M, Saito N, Nakagawa Y, Fukagawa M (2017) Continuous Glucose Monitoring Effects on Blood Glucose Management in Diabetic Patients on Hemodialysis-Results in the Patients from Single Hospital. J Diabetes Metab 8: $768 . \quad$ doi:

Page 2 of 6

alogliptin, $0.9 \mathrm{mg} /$ day voglibose, and $5 \mathrm{mg} /$ day linagliptin for the days of $\mathrm{HD}$ and non-HD, respectively, although 2 patients did not receive drug treatments. All 8 cases achieved tentative goal of glycemic control, as proposed by the Japanese Society for Dialysis Therapy. The patients were monitored again with CGM at 1 year after non-insulin therapy to evaluate the effects of replacement therapy. A questionnaire survey was also carried out to assess changes in dietary habits and motivation on self-management of type 2 diabetic patients after initiation of HD. HD was performed every other day in these 8 patients. Kindaly $2 \mathrm{E}^{\oplus}$ was used as the HD fluid in the study patients, with a glucose content of $100 \mathrm{mg} / \mathrm{dl}$. Medical examinations by diabetes specialists and educations about the nutrition by nutrition managers were carried out once a month (DM round). The study protocol was approved by the Ethics in Human Research Committee of our university and a signed consent form was obtained from each subject.

\section{Statistical analysis}

The results are presented as mean $\pm \mathrm{SD}$, and changes in parameters before and after switching therapy were compared using the Wilcoxon signed-rank test. A P value less than 0.05 was considered statistically significant.

\section{Results}

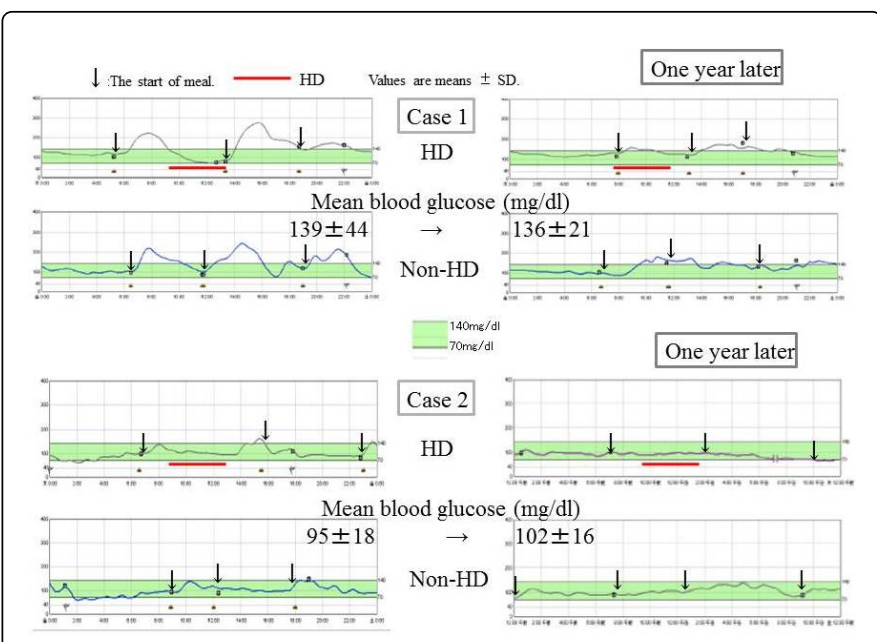

Figure 1: CGM records conducted at baseline and at end of the 1year study in case 1 and case 2 .

Figures 1-4 show sections of the CGM records conducted at baseline and at end of the 1-year study. The baseline characteristics and clinical data of the 8 patients are listed in Tables land 2. The mean glycated albumin (GA) level for the whole group at baseline was $17.9 \pm 3.2 \%$, while the baseline blood glucose level just before HD ( 2 hour after eating) was $137 \pm 19 \mathrm{mg} / \mathrm{dl}$. Although these levels were within the provisional target values of the Japanese Society for Dialysis Therapy (GA $<24.0 \%$, blood glucose just before HD $<180 \mathrm{mg} / \mathrm{dl}$ ), 7 of the 8 patients developed postprandial hyperglycemia (>200 mg/dl) after HD. These patients also did not achieve fasting glucose level of 80-110 $\mathrm{mg} / \mathrm{dl}$ and 2-h postprandial glucose level of $80-140 \mathrm{mg} / \mathrm{dl}$, which are recommended by the Japan Diabetes Society as "excellent" glucose target levels. Many patients were found to be anxious about SMBG monitoring mainly because they had not received any diabetes care since the commencement of HD.

\begin{tabular}{|c|c|}
\hline$n=8$ & Parameter Value \\
\hline Age (years) & $65.1 \pm 14.2$ \\
\hline Sex (males/females) & $6 / 2$ \\
\hline Duration of diabetes (years) & $24.6 \pm 7.3$ \\
\hline Duration of HD (years) & $5.9 \pm 1.6$ \\
\hline Retinopathy (+/-) & $10 / 0$ \\
\hline Duration of insulin therapy (years) & $7.5 \pm 5.2$ \\
\hline BMI $\left(\mathrm{kg} / \mathrm{m}^{2}\right)$ & $25.5 \pm 4.1$ \\
\hline Systolic/diastolic blood pressure $(\mathrm{mmHg})$ & $147 \pm 7 / 86 \pm 5$ \\
\hline $\mathrm{HbA} 1 \mathrm{c}(\%) / \mathrm{Hb}(\mathrm{g} / \mathrm{dl})$ & $5.5 \pm 0.6 / 10.8 \pm 0.6$ \\
\hline GA (\%)/Alb (g/dl) & $17.9 \pm 3.2 / 3.9 \pm 0.2$ \\
\hline Blood glucose (mg/dl) & $137.2 \pm 18.9$ \\
\hline Total cholesterol (mg/dl) & $174 \pm 28.8$ \\
\hline HDL-cholesterol (mg/dl) & $60.8 \pm 36.6$ \\
\hline GOT (U/l) & $13.5 \pm 6.2$ \\
\hline GPT (U/l) & $13.34 \pm 6.3$ \\
\hline Cardiovascular or hypoglycemia risk (+/-) & $7 / 3$ \\
\hline Fasting s-CPR (ng/ml) & $7.1 \pm 1.9$ \\
\hline \multicolumn{2}{|c|}{$\begin{array}{l}\text { Data are mean } \pm \text { SD or number of patients. } \\
\text { BMI: body mass index, HDL-cholesterol: high-density lipoprotein cholesterol, } \\
\text { GA: glycated albumin, GOT: glutamic oxaloacetic transaminase, GPT: glutamic } \\
\text { pyruvic transaminase, s-CPR: serum-connecting peptide immunoreactivity. } \\
\text { Cardiovascular or hypoglycemia risk: target GA levels of }<24.0 \% \text { are suggested } \\
\text { for HD patients with history of cardiovascular events and hypoglycemia by the } \\
\text { Japanese Society for Dialysis Therapy. }\end{array}$} \\
\hline
\end{tabular}

Table 1: Patient clinical characteristics at baseline.

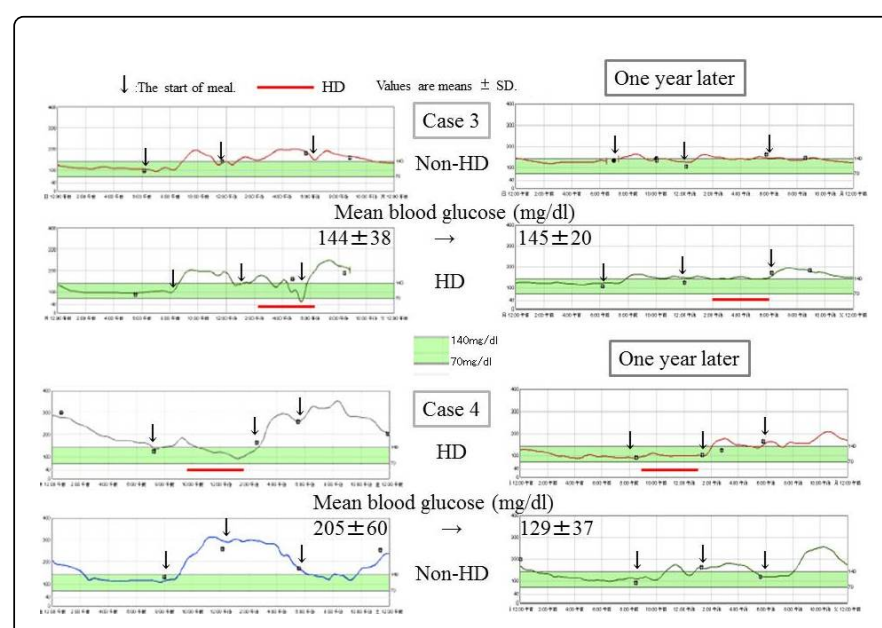

Figure 2: CGM records conducted at baseline and at end of the 1year study in case 3 and case 4 . 
Citation: Kimura M, Toyoda M, Saito N, Nakagawa Y, Fukagawa M (2017) Continuous Glucose Monitoring Effects on Blood Glucose Management in Diabetic Patients on Hemodialysis-Results in the Patients from Single Hospital. J Diabetes Metab 8: $768 . \quad$ doi: $10.4172 / 2155-6156.1000768$

Page 3 of 6

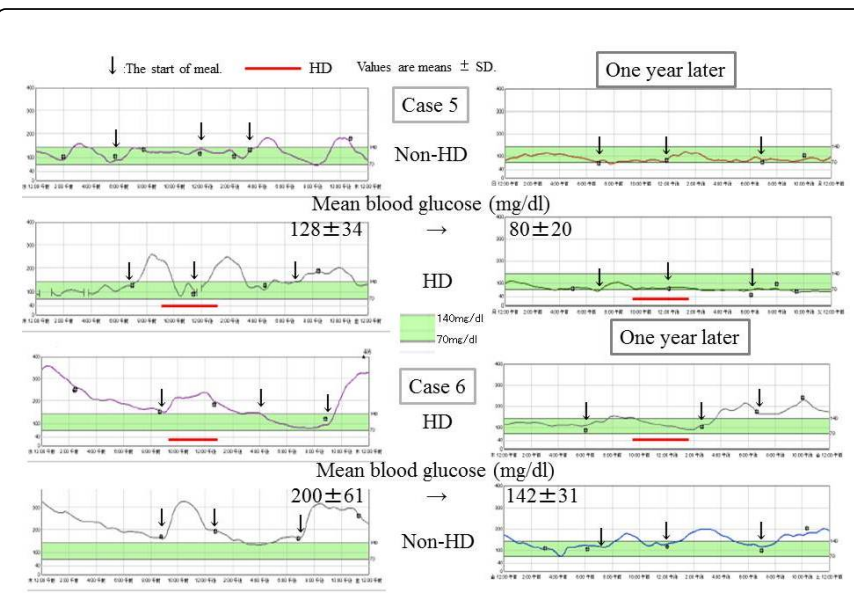

Figure 3: CGM records conducted at baseline and at end of the 1 year study in case 5 and case 6 .

\begin{tabular}{|l|l|l|l|}
\hline & Before CGM & After CGM & P \\
\hline Mean blood glucose level (mg/dl) & 153.4 & 125 & 0.027 \\
\hline SD $(\mathrm{mg} / \mathrm{dl})$ & 42 & 27 & 0.012 \\
\hline
\end{tabular}

Table 2: Mean blood glucose level and SD on CGM before and after.

Insulin therapy was restarted in 4 cases by their hope from each result of CGM. Subsequently, they were able to achieve the tentative goal of glycemic control proposed by the Japanese Society for Dialysis Therapy. Six of the 8 patients had fairly high postprandial glucose levels after HD. Their fasting glucose and 2-hrs postprandial glucose levels were within the "good" target glucose level recommended by the Japan Diabetes Society (Figures 1-4). CGM data showed a trend toward improvement in glucose fluctuation without hypoglycemia, and the mean blood glucose level decreased in 6 of 8 cases, together with a decrease in the variability, as reflected by a small SD of data of all patients. Mean blood glucose level and SD on CGM before and after switching therapy were considered statistically significant (Table 2).

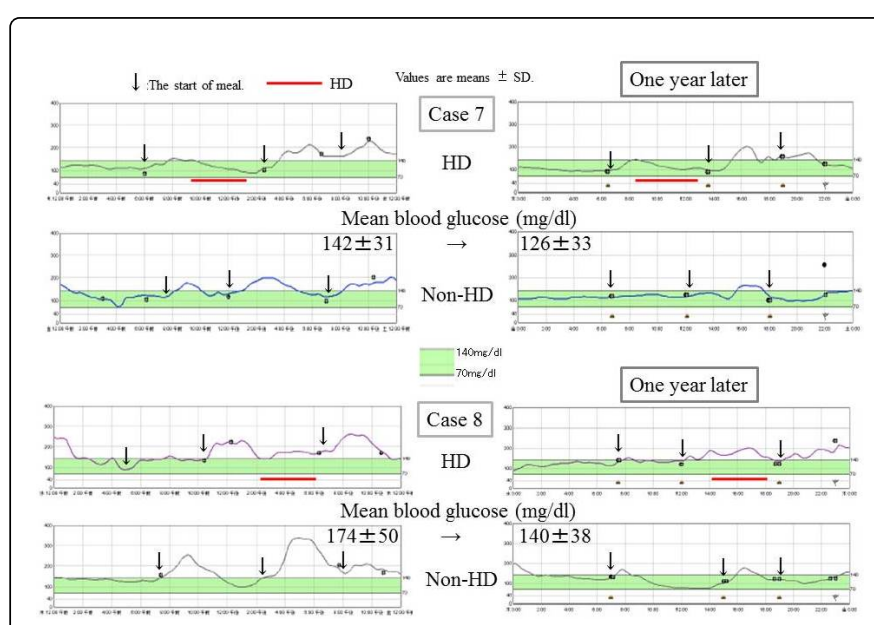

Figure 4: CGM records conducted at baseline and at end of the 1year study in case 7 and case 8 .

HbAlc level decreased in only 4 patients and glycated albumin levels decreased in only 6 patients, though larger changes were observed in both hemoglobin and albumin levels Table 3(i and ii) . Reductions in the doses of alogliptin and voglibose based on CGM data improved the number of hypoglycemic episodes and the severity of fluctuations in blood glucose levels. Furthermore, it seemed that education about regular nutrition by nutrition managers and round for diabetes mellitus (DM rounds) were also effective. In DM rounds, medical examinations by diabetes specialists were carried out once a month.

\begin{tabular}{|c|c|c|c|c|}
\hline & Case 1 & Case 2 & Case 3 & Case 4 \\
\hline Age (years) & 71 & 56 & 87 & 76 \\
\hline Sex & female & Male & male & female \\
\hline Duration of diabetes (years) & 13 & 21 & 27 & 32 \\
\hline Duration of HD (years) & 8 & 4 & 6 & 3 \\
\hline Retinopathy & + & + & + & + \\
\hline Duration of insulin therapy (years) & 6 & 2 & 6 & 7 \\
\hline Cardiovascular hypoglycemic risk & + & - & + & + \\
\hline Fasting s-CPR (ng/ml) & 9.8 & 5.9 & 5 & 8.4 \\
\hline \multicolumn{5}{|l|}{ CGM Before $\rightarrow$ After } \\
\hline BMI (kg/m2) & $17 \rightarrow 16$ & $20.0 \rightarrow 22.2$ & $19.5 \rightarrow 18$ & $26.3 \rightarrow 24.6$ \\
\hline $\begin{array}{l}\text { Systolic/diastolic blood pressure } \\
(\mathrm{mmHg})\end{array}$ & $150 / 90 \rightarrow 143 / 94$ & $140 / 80 \rightarrow 135 / 94$ & $150 / 90 \rightarrow 145 / 98$ & $140 / 90 \rightarrow 149 / 94$ \\
\hline $\mathrm{HbA} 1 \mathrm{c}(\%) / \mathrm{Hb}(\mathrm{g} / \mathrm{dl})$ & $4.8 / 10.0 \rightarrow 5.1 / 10.8$ & $4.8 / 11.4 \rightarrow 5.4 / 10.1$ & $5.2 / 10.2 \rightarrow 5.1 / 9.8$ & $5.7 / 10.6 \rightarrow 6.1 / 11.2$ \\
\hline
\end{tabular}


Citation: Kimura M, Toyoda M, Saito N, Nakagawa Y, Fukagawa M (2017) Continuous Glucose Monitoring Effects on Blood Glucose Management in Diabetic Patients on Hemodialysis-Results in the Patients from Single Hospital. J Diabetes Metab 8: $768 . \quad$ doi: $10.4172 / 2155-6156.1000768$

Page 4 of 6

\begin{tabular}{|c|c|c|c|c|}
\hline GA (\%) / Alb (g/dl) & $23.4 / 3.7 \rightarrow 19.1 / 4.1$ & $16.3 / 4.1 \rightarrow 16.2 / 3.8$ & $20.3 / 4.2 \rightarrow 19.2 / 4.1$ & $20.2 / 3.9 \rightarrow 19.4 / 3.9$ \\
\hline Blood glucose at start of $\mathrm{HD}(\mathrm{mg} / \mathrm{dl})$ & $147 \rightarrow 128$ & $112 \rightarrow 126$ & $143 \rightarrow 136$ & $140 \rightarrow 138$ \\
\hline Total cholesterol (mg/dl) & $136 \rightarrow 154$ & $194 \rightarrow 190$ & $169 \rightarrow 173$ & $191 \rightarrow 197$ \\
\hline HDL-cholesterol (mg/dl) & $45 \rightarrow 43$ & $51 \rightarrow 59$ & $77 \rightarrow 50$ & $34 \rightarrow 84$ \\
\hline GOT (U/I) & $10 \rightarrow 12$ & $10 \rightarrow 14$ & $9 \rightarrow 9$ & $13 \rightarrow 13$ \\
\hline GPT (U/I) & $8 \rightarrow 8$ & $19 \rightarrow 19$ & $12 \rightarrow 12$ & $7 \rightarrow 25$ \\
\hline Treatment for diabetes & $\begin{array}{l}\text { No medications } \\
\rightarrow \text { insulin + DM round }\end{array}$ & $\begin{array}{l}\text { Alogloptin: } 12.5 \mathrm{mg} \\
\rightarrow 6.25 \mathrm{mg}+\mathrm{DM} \text { round }\end{array}$ & $\begin{array}{l}\text { Voglibose: } 0.9 \mathrm{mg} \\
\rightarrow 0.6 \mathrm{mg}+\text { SMBG + DM } \\
\text { round }\end{array}$ & $\begin{array}{l}\text { Alogliptin: } 6.25 \mathrm{mg} \\
\rightarrow \text { Insulin }\end{array}$ \\
\hline
\end{tabular}

Table 3(i): Clinical data of the 8 patients (Cases 1-4).

\begin{tabular}{|c|c|c|c|c|}
\hline & Case 5 & Case 6 & Case 7 & Case 8 \\
\hline Age (years) & 40 & 62 & 76 & 53 \\
\hline Sex & male & Male & male & male \\
\hline Duration of diabetes (years) & 18 & 31 & 35 & 20 \\
\hline Duration of HD (years) & 6 & 6 & 7 & 7 \\
\hline Retinopathy & + & + & + & + \\
\hline Duration of insulin therapy (years) & 5 & 10 & 20 & 4 \\
\hline Cardiovascular hypoglycemic risk & - & + & + & + \\
\hline Fasting s-CPR (ng/ml) & 7.2 & 8.1 & 8.3 & 3.8 \\
\hline \multicolumn{5}{|l|}{ CGM Before $\rightarrow$ After } \\
\hline $\mathrm{BMI}\left(\mathrm{kg} / \mathrm{m}^{2}\right.$ & $26.9 \rightarrow 26.9$ & $24.4 \rightarrow 22.5$ & $22.9 \rightarrow 22.7$ & $23.1 \rightarrow 22.8$ \\
\hline $\begin{array}{l}\text { Systolic/diastolic blood pressure } \\
(\mathrm{mmHg})\end{array}$ & $150 / 90 \rightarrow 150 / 92$ & $148 / 90 \rightarrow 145 / 94$ & $160 / 80 \rightarrow 173 / 60$ & $140 / 80 \rightarrow 138 / 84$ \\
\hline $\mathrm{HbA} 1 \mathrm{c}(\%) / \mathrm{Hb}(\mathrm{g} / \mathrm{dl})$ & $5.6 / 11.4 \rightarrow 5.4 / 10.1$ & $6.8 / 11.7 \rightarrow 5.6 / 10.6$ & $5.4 / 10.2 \rightarrow 5.5 / 9.5$ & $5.6 / 10.6 \rightarrow 5.3 / 10.8$ \\
\hline GA (\%)/Alb (g/dl) & $18.1 / 3.8 \rightarrow 19.2 / 3.8$ & $12.3 / 3.8 \rightarrow 18.4 / 4.0$ & $16.5 / 3.8 \rightarrow 15.9 / 3.4$ & $16.4 / 4.1 \rightarrow 13.1 / 3.7$ \\
\hline $\begin{array}{l}\text { Blood glucose at the start of } \mathrm{HD} \\
(\mathrm{mg} / \mathrm{dl})\end{array}$ & $133 \rightarrow 142$ & $158 \rightarrow 140$ & $104 \rightarrow 127$ & $160 \rightarrow 147$ \\
\hline Total cholesterol (mg/dl) & $134 \rightarrow 112$ & $201 \rightarrow 203$ & $152 \rightarrow 149$ & $215 \rightarrow 198$ \\
\hline HDL-cholesterol (mg/dl) & $152 \rightarrow 72$ & $37 \rightarrow 81$ & $47 \rightarrow 83$ & $43 \rightarrow 38$ \\
\hline GOT (U/I) & $28 \rightarrow 22$ & $18 \rightarrow 18$ & $8 \rightarrow 6$ & $12 \rightarrow 12$ \\
\hline GPT (U/I) & $19 \rightarrow 19$ & $25 \rightarrow 25$ & $8 \rightarrow 8$ & $9 \rightarrow 10$ \\
\hline Treatment for diabetes & $\begin{array}{l}\text { Alogloptin: } 6.25 \mathrm{mg} \\
\rightarrow \text { Alogliptin: } 6.25 \mathrm{mg}+\mathrm{DM} \\
\text { round }\end{array}$ & $\begin{array}{l}\text { Linagliptin: } 5 \mathrm{mg} \\
\rightarrow \text { insulin + DM round }\end{array}$ & $\begin{array}{l}\text { No medications } \\
\rightarrow \text { no medications }\end{array}$ & $\begin{array}{l}\text { Vildagliptin: } 50 \mathrm{mg} \\
\rightarrow \text { Insulin + DM round }\end{array}$ \\
\hline \multicolumn{5}{|c|}{$\begin{array}{l}\text { DM round was carried out medical examinations by diabetes specialists and educations about the nutrition by nutrition managers once a month. } \\
\text { Kindaly } 2 \mathrm{E} \circledast \text { was used as the dialysis fluid in each patient. Glucose content is } 100 \mathrm{mg} / \mathrm{dl} \text {. }\end{array}$} \\
\hline
\end{tabular}

Table 3(ii): Clinical data of the 8 patients (Case 5-8). 
Citation: Kimura M, Toyoda M, Saito N, Nakagawa Y, Fukagawa M (2017) Continuous Glucose Monitoring Effects on Blood Glucose Management in Diabetic Patients on Hemodialysis-Results in the Patients from Single Hospital. J Diabetes Metab 8: $768 . \quad$ doi: 10.4172/2155-6156.1000768

Page 5 of 6

The response to the questionnaire showed that most cases favored continuation of SMBG because it improved problems related to their dietary habits (Table 3). The response to the questionnaire in the present study showed that most patients desired continuation of SMBG because it improved problematic dietary habits (Table 4).

\begin{tabular}{|l|l|l|l|}
\hline & Improve & Worse & Invariable \\
\hline Before CGM & & & \\
\hline Dietary habits & 0 & 8 & 0 \\
\hline Self-management of diabetes & 0 & 7 & 1 \\
\hline Anxious about diabetes management & 8 & 0 & 0 \\
\hline After CGM & & & \\
\hline Dietary habits & 6 & 0 & 2 \\
\hline Self-management of diabetes & 6 & 0 & 2 \\
\hline Anxious of diabetes management & 0 & 6 & 2 \\
\hline Data are number of patients. & & & \\
\hline
\end{tabular}

Table 4: Questionnaire on CGM before and after-Changes in consciousness after initiation of HD.

\section{Discussion}

Patients with long history of diabetes, known history of severe hypoglycemia, advanced atherosclerosis, advanced age, or frailty may benefit from less aggressive glycemic target [5]. Furthermore, patients with diabetic nephropathy can develop treatment-related serious hypoglycemia due to poor renal clearance of insulin and augmented drug efficacy, often resulting in withdrawal of insulin. Consequently, many patients on HD are erroneously switched to oral glucoselowering agents or diet therapy alone, without SMBG. In this study, diabetic patients on HD who did not use SMBG after withdrawal of insulin were recruited for measurement and evaluation of blood glucose with CGM. Insulin therapy and SMBG were restarted in 5 patients, and they were subsequently able to achieve the recommended goal of glycemic control proposed by the Japanese Society for Dialysis Therapy. They also achieved "good" fasting glucose and 2-hours postprandial glucose levels recommended by the Japan Diabetes Society. CGM data showed a trend toward improvement in glucose fluctuation without hypoglycemia, as evident by a decrease in mean blood glucose in 6 of the 8 patients and low SD of the group.

The control of blood glucose level of diabetic patients on HD is difficult, due to frequent hypoglycemic episodes, restricted use of antidiabetic agents, and fluctuations in blood glucose, insulin, and drug metabolite levels between the day of HD and the non-HD day.

The presence of diabetes increases the risk of mortality among the HD patients [6]; and HbAlc value $>7.5 \%$ also increases the risk of mortality among diabetic patients on HD [7]. In this study, HbAlc was $<6.2 \%$ in all patients and did not pose a higher mortality risk, though the hemoglobin level was low in all patient. Shortened life span of erythrocytes and increased erythropoiesis [3] are reported in patients with end-stage renal failure (ESRF), and both can falsely lower $\mathrm{HbAlc}$ values by reducing the erythrocyte glycemic exposure time. For this reason, previous studies recommended the use of GA as a more accurate indicator of blood glucose level in diabetic patients on HD. The tentative target for glycemic control in HD patients is GA level $<20.0 \%$ as recommended by the Japanese Society for Dialysis Therapy. Furthermore, target GA levels of $<24.0 \%$ are suggested for HD patients with history of cardiovascular events and hypoglycemia. However, since diabetic nephropathy is associated with nephrosis, serum albumin level is not helpful as a marker for blood glucose level. Among our patients, many showed changes in hemoglobin and albumin levels (Table 3).

For these reasons, blood glucose levels should be measured in diabetic HD patients by SMBG and withdrawal of blood samples. The Japanese Society for Dialysis Therapy recommends the following tentative targets for glycemic control: predialysis casual plasma glucose level (or 2-h postprandial plasma glucose level) of $<180-200 \mathrm{mg} / \mathrm{dL}$. In all 8 patients, GA and blood glucose measured just before HD (2 hour after eating) were within the provisional target values of the Japanese Society for Dialysis Therapy (GA $<24.0 \%$, blood glucose just before HD $<180 \mathrm{mg} / \mathrm{dl}$ ). However, 6 of the 8 patients had postprandial hyperglycemia $(>200 \mathrm{mg} / \mathrm{dl})$ after HD based on the CGM records. Thus, it would not have been possible to confirm these results without CGM monitoring.

Postprandial hyperglycemia after HD confirmed by CGM may account for the increased risk of cardiovascular complications. Hypoglycemia is also harmful, irrespective of whether it occurs during or following HD. However, the rapid rise in blood glucose after hypoglycemia and related glycemic fluctuations may account for the increased cardiovascular risk in type 2 diabetic patients [8-10]. Circulating glucose concentrations are likely to drop significantly during HD. The large difference in glucose levels between plasma and the dialysate affects the change in glucose levels during HD: the higher the glucose level at HD initiation, the greater the decrease during HD. The possible mechanisms for this decrease include glucose loss in the dialytic effluent fluid and excessive consumption of glucose as a result of accelerated anaerobic metabolism in HD patients [11-14]. The postprandial hyperglycemia after HD may be caused by increased secretion of counter-regulatory hormones, such as glucagon, adrenocorticotrophic hormone, and cortisol, which restore glycemic levels after recovery from hypoglycemia or lowering of blood pressure during HD [15].

Not only hypoglycemia but also CGM can confirm difficult hyperglycemia. Based on these results, we consider CGM is important for the regulation of blood glucose level in diabetic patients undergoing HD.

\section{Conclusion}

Diabetic patients on HD require careful monitoring of glucose level during HD with SMBG, CGM, and direct blood glucose measurement before any decision is made regarding withdrawal of insulin and cessation of SMBG. Even in terms of response to the patient views, the 
Citation: Kimura M, Toyoda M, Saito N, Nakagawa Y, Fukagawa M (2017) Continuous Glucose Monitoring Effects on Blood Glucose Management in Diabetic Patients on Hemodialysis-Results in the Patients from Single Hospital. J Diabetes Metab 8: $768 . \quad$ doi:

response to the questionnaire provides important information about the patient that should be taken into consideration since diabetes is a self-management disease. The glycemic targets of diabetic patients undergoing HD should only be set after careful and thorough consideration of the individual case. Furthermore, the dialysis physician should provide appropriate diabetes care to HD patients in consultation with the diabetes specialist.

\section{Acknowledgments}

We are grateful to all patients for participating in this study and cooperation of nurses and other healthcare professionals

\section{Conflict of Interest}

The authors declare no conflict of interests in relation to this article.

\section{References}

1. Nakao T, Inaba M, Abe M, Kaizu K, Shima K, et al. (2012) Best Practice for Diabetic Patients on Hemodialysis. Ther Apher Dial 19: 40-66.

2. Terawaki Y, Nomiyama T, Akehi Y, Takenoshita H, Nagaishi R, et al. (2013) The efficacy of incretin therapy in patients with type 2 diabetes undergoing hemodialysis. Diabetol Metab Syndr 5: 10.

3. Kazempour-Ardebili S, Lecamwasam VL, Dassanyake T, Frankel AH, Tam FW, et al. (2009) Assessing glycemic control in maintenance hemodialysis patients with type 2 diabetes. Diabetes Care 32: 1137-1142.

4. Kishimoto M, Noda M (2014) Glucose management in diabetic patients undergoing hemodialysis. Diabetol Int 5: 84-91.

5. Ismail-Beigi F (2012) Clinical practice. Glycemic management of type 2 diabetes mellitus. N Engl J Med 366: 1319-1327.

6. Morioka T, Emoto M, Tabata T, Shoji T, Tahara H, et al. (2001) Glycemic control is a predictor of survival for diabetic patients on hemodialysis. Diabetes Care 24: 909-913.
7. Young EW, Goodkin WA, Mapes DL, Port FK, Keen ML, et al. (2000) The Dialysis Outcomes and Practice Patterns Study (DOPPS): an international hemodialysis study. Kidney Int 57: S74-S81.

8. Mirani M, Berra C, Finazzi, Calvetta A, Radaelli MG, et al. (2010) Interday glycemic variability assessed by continuous glucose monitoring in insulin-treated type 2 diabetes patients on hemodialysis. Diabetes Technol Ther 12: 749-753.

9. Ceriello A, Novials A, Ortega E, La Sala L, Pujadas G, et al. (2012) Evidence that hyperglycemia after recovery from hypoglycemia worsens endothelial function and increases oxidative stress and inflammation in healthy control subjects and subjects with type 1 diabetes. Diabetes 61: 2993-2997.

10. Wright RJ, Frier BM (2008) Vascular disease and diabetes: is hypoglycaemia an aggravating factor? Diabetes Metab Res Rev 24: 353-363.

11. Schmitz O (1991) Glucose metabolism in non-diabetic and insulindependent diabetic subjects with end-stage renal failure. Dan Med Bull 38: 36-52.

12. Jackson MA, Holland MR, Nicholas J, Lodwick R, Forster D, et al. (2000) Hemodialysis-induced hypoglycemia in diabetic patients. Clin Nephrol 54: 30-34.

13. Takahashi A, Kubota T, Shibahara N, Terasaki J, Kagitani M, et al. (2004) The mechanism of hypoglycemia caused by hemodialysis. Clin Nephrol 62: $362-368$.

14. Burmeister JE, Scapini A, da Rosa Miltersteiner D, da Costa MG, Campos BM (2007) Glucose-added dialysis fluid prevents asymptomatic hypoglycaemia in regular haemodialysis. Nephrol Dial Transplant 22: 1184-1189.

15. Abe M, Kaizu K, Matsumoto K (2007) Evaluation of the hemodialysisinduced changes in plasma glucose and insulin concentrations in diabetic patients: comparison between the hemodialysis and non-hemodialysis days. Ther Apher Dial 11: 288-295. 